\title{
Changes in Heart Function in Patients with Heart Failure after the Completion of Land-Based and Partial Water-Based Exercise Programmes
}

\section{Mourot $\mathrm{L}^{* 1,2}$ and Monpère $\mathrm{C}^{3}$}

${ }^{1}$ EA 4660 Culture, Sport, Health, Society and Exercise Performance, Health Innovation platform, University of Franche-Comté, Besançon, France

${ }^{2}$ Clinical Investigation Centre in Technological Innovation, INSERM CIT808, University Hospital of Besançon, France

${ }^{3}$ Cardiovascular Rehabilitation Centre Bois Gibert, Ballan-Miré, France

${ }^{*}$ Corresponding author: Mourot L UFR SMP, 19 rue Ambroise Paré Plateforme Exercice Performance Santé innovation (EPSI) - Bâtiment Socrate Bureau 24525030 Besançon Cedex, Tel: +33 3630823 21, E-mail: laurent.mourot@univ-fcomte.fr

Citation: Mourot L, Monpère C (2014) Changes in Heart Function in Patients with Heart Failure after the Completion of Land-Based and Partial Water-Based Exercise Programmes. J Clin Exp Res Cardiol 1(1): 105. doi: 10.15744/2394-6504.1.105

Received Date: August 29, 2014 Accepted Date: September 05, 2014 Published Date: September 26, 2014

\section{Abstract}

Background: Opinion is divided as to the changes in ventricular function brought about by exercise, with few studies on water-based exercise programmes for heart-failure patients. This study investigates whether following a partial water-based exercise programme could lead to an earlier improvement in ventricular function in heart-failure patients compared with a land-based exercise programme.

Methods: The randomized clinical trial involved 24 heart-failure patients (ejection fraction $<40 \%$, functional class II or III), who participated in two exercise programmes (land-based or partial water-based) lasting three weeks.

Results: We observed an increase in ejection fraction $(2.19 \pm 0.77 \%$; $=0.009)$, posterior wall thickness $(0.79 \pm 0.23 \mathrm{~mm} ; \mathrm{p}=0.002)$ and mitral A wave duration $(7.38 \pm 2.56 \mathrm{~ms} ; \mathrm{p}=0.009)$ and a decrease in the difference in duration between the pulmonary A wave period and the mitral A wave one $(-5.33 \pm 2.50 \mathrm{~ms} ; \mathrm{p}=0.043)$ in both groups after the exercise programme had been completed. We also saw a significant increase in plasma nitrate concentration levels. Only the ratio of peak E wave (early or rapid-filling) velocity to early diastolic flow propagation velocity, the diameter of the inferior vena cava and the thickness of the posterior wall give different results depending on the exercise programme followed.

Conclusions: Changes in ventricular function show early improvement in systolic and diastolic function independently of the type of exercise, but it seems to be that, depending on the design of the programme, different adaptive mechanisms are set in motion.

Keywords: Echocardiography; Exercise; Heart failure; Rehabilitation

\section{Introduction}

Ventricular function is complex and its study in heart patients [1-3] of great importance. Advances in our understanding of ventricular dysfunction have allowed us to bring in new treatments and/or to improve existing ones.

Among the different treatment options are the exercise programmes included on cardiac rehabilitation programmes [4-6].

According to various studies, therapeutic exercise improves $\mathrm{VO}_{2}$, muscular strength and muscle mass, functional class (i.e. New York Heart Association categories) and quality of life in patients with heart failure; it also restores autonomic, neurohormonal and haemodynamic function, [7-9] improving survival in these patients [10,11]. However, while some authors have observed ventricular remodelling in clinically stable patients $[12,13]$, other studies have not identified any benefits for heart function $[14,15]$, and opinion is divided as to the changes taking place in systolic and/or diastolic function.

Although immersion in water used to be considered dangerous for patients with heart failure $[6,16]$ recent studies have shown that water-based exercise programmes are safe for stable class II or III patients [17-19]. However, there are few such studies about the effects of immersion in water [20-22].

For this reason it is vitally important for the design and prescription of exercise programmes for patients with heart disease that we know and understand what changes take place in ventricular function in response to different exercise programs [23].

In light of the above, we need to consider whether following a partial water-based exercise programme could lead to an early improvement in systolic and diastolic function in heart-failure patients as compared to taking part in a land-based exercise programmes. 
The aim of this study is to analyse the changes in ventricular function in patients with heart failure taking part in a three-week exercise programme carried out primarily on land or partly in water, and to compare the differences between the two.

\section{Methods}

\section{Study Population}

The study was carried out on a sample of 24 patients with stable heart failure involving left ventricular systolic dysfunction (ejection fraction (EF) $\leq 40 \%$ ) and New York Heart Association (NYHA) class II or III. All the patients underwent coronary angiography. The patients' characteristics are shown in Table 1.

\begin{tabular}{|c|c|c|}
\hline & \multicolumn{2}{|c|}{ Patients with Heart Failure $(n=24)$} \\
\hline & $\begin{array}{c}\text { Water-based exercise } \\
\text { programme }(n=12)\end{array}$ & $\begin{array}{c}\text { Land-based exercise } \\
\text { programme }(n=12)\end{array}$ \\
\hline Age (years) & $51.7 \pm 3.6$ & $53.3 \pm 4.2$ \\
\hline Height $(\mathrm{cm})$ & $175.3 \pm 2.1$ & $169.8 \pm 1.3$ \\
\hline Weight (kg) & $78.6 \pm 2.5$ & $76.1 \pm 2.1$ \\
\hline BMI (kg) & $25.6 \pm 0.8$ & $26.4 \pm 0.8$ \\
\hline EF & $30.2 \pm 2.0$ & $28.9 \pm 2.2$ \\
\hline $\mathrm{VO}_{2}$ peak $\left(\mathrm{ml} \mathrm{min}^{-1} \cdot \mathrm{kg}^{-1}\right)$ & $20.0 \pm 2.1$ & $18.2 \pm 1.6$ \\
\hline \multicolumn{3}{|l|}{ Aetiology of Heart failure } \\
\hline Ischaemic heart disease & 8 & 7 \\
\hline Dilated cardiomyopathy & 4 & 5 \\
\hline \multirow[t]{2}{*}{ NYHA } & II $(\mathrm{n}=1)$ & II $(\mathrm{n}=2)$ \\
\hline & III $(n=11)$ & III $(n=10)$ \\
\hline \multicolumn{3}{|l|}{ Medication } \\
\hline B-blockers (n) & 11 & 12 \\
\hline Vasodilators $^{*}(\mathrm{n})$ & 9 & 11 \\
\hline Diuretics (n) & 6 & 8 \\
\hline Anti-aldosterone (n) & 2 & 7 \\
\hline Digitalis (n) & 2 & - \\
\hline Statins (n) & 9 & 9 \\
\hline Oral anti-diabetic drug (n) & - & 2 \\
\hline Insulin (n) & - & 1 \\
\hline Omega 3 fatty acids (n) & 1 & 2 \\
\hline \multicolumn{3}{|l|}{ Risk factors } \\
\hline Smoking (n) & 8 & 7 \\
\hline Diabetes (n) & 1 & 3 \\
\hline Hereditary (n) & 5 & 6 \\
\hline Excess weight (n) & 4 & 6 \\
\hline Dyslipidaemia (n) & 5 & 7 \\
\hline Cholesterol (g/l) & $1.7 \pm 0.4$ & $1.9 \pm 0.4$ \\
\hline Cholesterol-HDL (g/l) & $0.4 \pm 0.1$ & $0.5 \pm 0.1$ \\
\hline Cholesterol-LDL (g/l) & $1.0 \pm 0.3$ & $1.1 \pm 0.3$ \\
\hline Triglycerides (g/l) & $1.8 \pm 1.1$ & $1.5 \pm 1.4$ \\
\hline
\end{tabular}

BMI, body mass index; EF, ejection fraction; $\mathrm{VO}_{2 \text { peak }}$, peak oxygen consumption during stress test; NYHA, New York Heart Association Functional Class.

* Angiotensin-converting enzyme inhibitors and angiotensin II receptor antagonists

Table 1: Characteristics of the study population

Only those patients who were clinically stable after two weeks, and who also had a stable sinus rhythm, as indicated by ECG, and stable medical treatment, were included in the study. All of them took part in a cardiac rehabilitation programme lasting three weeks. These patients had not previously taken part in similar studies. Those patients with contraindications for the stress test or whose stress test was ended because of complications such as residual myocardial ischaemia or complex ventricular arrhythmia were also excluded. Patients were also left out if they suffered from a water phobia, skin condition, urinary incontinence, underwent significant changes in treatment or had other illnesses that might interfere with the protocol. 
The study protocol complies with the Declaration of Helsinki and was reviewed and accepted by the Tours Ethics Committee (France; no. 2005-2025). The participants were provided with information about the study methods and gave their informed consent in writing.

\section{Study design}

The study was carried out at the Bois Gibert cardiac preventive care and rehabilitation centre in Ballan-Miré, France. When a patient met the inclusion criteria and signed the document giving informed consent, he or she would join the study. The patients were randomly assigned to one of two groups which determined whether they would take part in the entirely land-based rehabilitation programme (aerobic exercise (cycle ergometer) and callisthenic exercises) or the partly water-based one (land-based aerobic exercise (cycle ergometer) and water-based callisthenic exercises). The randomisation process for each group was done by a computer generating random numbers.

\section{Intervention}

Each patient's rehabilitation programme consisted of land-based aerobic exercises using a cycle ergometer (30 minutes, five times a week, at $60-70 \% \mathrm{VO}_{2 \max }$ intensity), in addition to 50-minute gymnastic exercise sessions (callisthenic exercises) five times a week at an individualized target intensity heart rate recorded at the ventilatory threshold. These callisthenic exercises were land-based for half of the participants and water-based for the other half.

The water-based exercises took place in a $1.3 \mathrm{~m}$-deep pool in the Bois Gibert cardiovascular rehabilitation centre. The water temperature was $30-32{ }^{\circ} \mathrm{C}$ and the ambient temperature $25-26^{\circ} \mathrm{C}$.

The exercises were done standing up no matter whether they were taking place on land or in water. The callisthenic exercise programme would start off with a five-minute warm-up followed by 25 minutes of different exercises involving upper and lower extremity and trunk muscle groups and which gradually built in intensity, with the number of repetitions and the speed increasing. The sessions would end with five minutes' recovery or cooling down time. At all times patients would coordinate their breathing (breathing in and breathing out) with the movements they were making.

All the sessions were led and supervised by a physiotherapist and involved heart rate monitoring of all patients (Polar Electro Oy, Kempele, Finland) with the aim of maintaining the exercise intensity at the training heart rate set for each case.

All the patients attended the whole multidisciplinary cardiac rehabilitation programme, including sessions on education and secondary prevention.

\section{Measurement}

Echocardiographic measurements were taken for all patients using an Acuson Sequoia C-256 system (Siemens, New York) with a 3.5- $\mathrm{MHz}(3 \mathrm{~V} 2 \mathrm{C})$ transducer using harmonic imaging techniques.

Measurements were taken at the start, in the three weeks prior to beginning the programme and at the end of the study. The patients were studied lying on their left sides breathing calmly. They underwent transthoracic two-dimensional echocardiography on the long and short parasternal axes, with apical four- and two-chamber views being obtained in order to determine the diameters of the left ventricle (telediastolic diameter (TDD) and telesystolic diameter (TSD)), the thickness of the posterior wall (PW) and the interventricular septum, the diameter of the inferior vena cava (IVC) and the ejection fraction (EF).

The following were recorded on the Doppler echocardiogram using an apical four-chamber view: peak flow velocity during early or rapid filling (E); peak flow velocity during late filling or atrial contraction (A); peak velocity of the pulmonary systolic (S) wave and the diastolic (D) wave; early diastolic flow propagation velocity (Vp); mitral valve deceleration time (DT); peak E wave velocity of the mitral annulus (E'); duration of the pulmonary A wave (Ap); and duration of the mitral A wave (Am). Also calculated were velocity filling curves for transmitral flow using the E/A and E/E' ratios, peak early or rapid filling E wave velocity in relation to early diastolic propagation flow (E/Vp) and the difference in duration between the pulmonary and mitral wave periods (Ap-Am).

The levels of oxidised nitric oxide (NO) metabolites were also recorded, both at the beginning and at the end of the study, using a chemiluminescence NO analyser (NOA280, Sievers Instruments, Boulder, Colorado, USA). All the patients had the same meals during the protocol period to ensure that nutrients did not interfere with changes in NO metabolites.

Plasma noradrenaline, adrenaline and dopamine concentrations were determined using a sensitive and specific radioenzymatic assay method [24].

\section{Statistical analysis}

To compare the changes observed in variables depending on the types of intervention, a two-way repeated measure analysis of variance was used having first checked, using the Shapiro-Wilk test, that there was no evidence to suggest that these changes violated normality. 
To study associations between changes in the variables analysed we used the Pearson linear correlation coefficient.

The significance level used in the hypothesis contrasts is the standard $\mathrm{p}<0.05$ one.

\section{Results}

An analysis of the distribution of changes in the variables studied shows no evidence to suggest that either group diverges from normality.

Patients with heart failure showed an increase in EF, PW and Am as well as a decrease in Ap-Am after completing the exercise programme $(\mathrm{p}<0.05)$, although only the changes seen in the PW differ according to the exercise programme followed (Table 2$)$. The $\mathrm{E} / \mathrm{Vp}$ ratio also gives different answers depending on the exercise programme. The diameter of the IVC decreased in both groups, but the difference was greater in the group which did water-based exercise compared with the land-based exercise programme.

\begin{tabular}{|c|c|c|c|c|c|c|}
\hline \multicolumn{7}{|c|}{ Heart-Failure Patients $(n=24)$} \\
\hline & \multicolumn{3}{|c|}{ Water-based exercise program $(n=12)$} & \multicolumn{3}{|c|}{ Land-based exercise program $(n=12)$} \\
\hline & Start & Finish & $\begin{array}{c}\text { Relative } \\
\text { difference (\%) }\end{array}$ & Start & Finish & $\begin{array}{c}\text { Relative } \\
\text { difference (\%) }\end{array}$ \\
\hline TDD (mm) & $66.8 \pm 9.0$ & $66.5 \pm 7.9$ & $-0.3 \pm 0.7$ & $66.1 \pm 7.9$ & $66.5 \pm 6.1$ & $0.4 \pm 0.8$ \\
\hline TSD (mm) & $50.3 \pm 11.6$ & $50.1 \pm 9.5$ & $-0.3 \pm 1.5$ & $51.1 \pm 9.6$ & $50.1 \pm 6.8$ & $-1.0 \pm 1.1$ \\
\hline EF (\%) & $30.2 \pm 6.7$ & $33.2 \pm 7.3 \mathrm{a}$ & $3.0 \pm 0.8$ & $28.9 \pm 7.0$ & $30.5 \pm 5.1 \mathrm{a}$ & $1.3 \pm 1.3$ \\
\hline IVS (mm) & $10.7 \pm 1.2$ & $10.1 \pm 0.8$ & $-0.6 \pm 0.3$ & $8.9 \pm 1.1 \mathrm{~b}$ & $8.8 \pm 1.0 \mathrm{~b}$ & $-0.1 \pm 0.3$ \\
\hline PW (mm) & $8.9 \pm 1.0$ & $9.2 \pm 1.1$ & $0.3 \pm 0.3$ & $8.0 \pm 1.3$ & $9.3 \pm 1.1 \mathrm{a}$ & $1.3 \pm 0.3 b$ \\
\hline $\mathrm{A}(\mathrm{cm} / \mathrm{sg})$ & $0.47 \pm 0.21$ & $0.49 \pm 0.18$ & $0.0 \pm 0.0$ & $0.63 \pm 0.21$ & $0.57 \pm 0.25$ & $-0.1 \pm 0.1$ \\
\hline $\mathrm{E}(\mathrm{cm} / \mathrm{sg})$ & $0.69 \pm 0.17$ & $0.72 \pm 0.20$ & $0.0 \pm 0.1$ & $0.82 \pm 0.35$ & $0.80 \pm 0.33$ & $-0.1 \pm 0.0$ \\
\hline E/A & $2.0 \pm 1.4$ & $1.8 \pm 1.0$ & $-0.3 \pm 0.3$ & $1.6 \pm 1.2 \mathrm{~b}$ & $1.7 \pm 1.5 \mathrm{a}$ & $-0.0 \pm 0.2$ \\
\hline $\mathrm{S}(\mathrm{cm} / \mathrm{sg})$ & $0.48 \pm 0.15$ & $0.46 \pm 0.08$ & $0.0 \pm 0.0$ & $0.49 \pm 0.06$ & $0.53 \pm 0.09$ & $0.0 \pm 0.0$ \\
\hline $\mathrm{D}(\mathrm{cm} / \mathrm{sg})$ & $0.66 \pm 0.26$ & $0.65 \pm 0.29$ & $-0.0 \pm 0.1$ & $0.53 \pm 0.25$ & $0.61 \pm 0.23$ & $0.1 \pm 0.0$ \\
\hline Am (ms) & $113.4 \pm 18.5$ & $119.6 \pm 14.9 \mathrm{a}$ & $6.2 \pm 2.7$ & $117.4 \pm 19.2$ & $126.0 \pm 18.2 \mathrm{a}$ & $8.6 \pm 4.5$ \\
\hline Ap (ms) & $140.7 \pm 13.6$ & $142.2 \pm 13.7$ & $1.5 \pm 5.2$ & $145.0 \pm 16.0$ & $147.6 \pm 18.8$ & $2.6 \pm 3.6$ \\
\hline Ap-Am (ms) & $30.1 \pm 16.9$ & $22.6 \pm 12.5 \mathrm{a}$ & $-5.8 \pm 3.5$ & $27.6 \pm 12.9$ & $21.6 \pm 12.1 \mathrm{a}$ & $-4.8 \pm 3.7$ \\
\hline $\mathrm{E}^{\prime}(\mathrm{cm} / \mathrm{sg})$ & $0.69 \pm 0.17$ & $0.72 \pm 0.20$ & $1.3 \pm 1.4$ & $0.82 \pm 0.35$ & $0.80 \pm 0.33$ & $1.6 \pm 0.8$ \\
\hline $\mathrm{E} / \mathrm{E}^{\prime}$ & $5.6 \pm 2.1$ & $5.9 \pm 2.4$ & $0.1 \pm 0.8$ & $11.9 \pm 7.7$ & $10.0 \pm 6.5$ & $-2.5 \pm 0.9$ \\
\hline $\mathrm{Vp}(\mathrm{cm} / \mathrm{sg})$ & $39.3 \pm 7.5$ & $36.2 \pm 7.6$ & $-2.2 \pm 2.0$ & $35.9 \pm 7.9$ & $36.0 \pm 6.0$ & $1.0 \pm 2.7$ \\
\hline $\mathrm{E} / \mathrm{Vp}$ & $1.8 \pm 0.6$ & $4.9 \pm 9.7$ & $0.3 \pm 0.1$ & $2.4 \pm 1.0$ & $2.2 \pm 0.7$ & $-0.3 \pm 0.2 b$ \\
\hline IVC (mm) & $15.5 \pm 4.1$ & $13.7 \pm 4.0 \mathrm{a}$ & $-2.6 \pm 1.1$ & $13.0 \pm 3.5$ & $12.8 \pm 3.1$ & $-0.1 \pm 0.4 b$ \\
\hline DT (ms) & $149.0 \pm 46.0$ & $162.7 \pm 45.0$ & $13.7 \pm 9.1$ & $162.6 \pm 94.3$ & $174.2 \pm 51.0$ & $14.9 \pm 29.8$ \\
\hline
\end{tabular}

TDD, telediastolic diameter; TSD, telesystolic diameter; EF, ejection fraction; IVS, interventricular septum thickness; PW, posterior wall thickness; A, latefilling wave; E, early-filling wave; E/A, ratio of early to late mitral flow wave; S, peak systolic velocity; D, peak diastolic velocity; Am, mitral A wave duration; Ap, pulmonary A wave duration; Ap-Am, difference in duration between the pulmonary and mitral A waves; $\mathrm{E}^{\prime}$, peak E wave velocity of the mitral annulus by Doppler tissue imaging; E/E', ratio of mitral E wave velocity to Doppler tissue (DTI) mitral annular E' wave; $\mathrm{Vp}$, colour M-mode propagation velocity; E/Vp, ratio of E wave mitral flow to colour M-mode propagation velocity; IVC, inferior vena cava diameter; DT, deceleration time.

a significantly different from the Start value in the same group at the $\mathrm{p}<0.05$ level; b significantly different from the corresponding value in the Water-based exercise program group at the $\mathrm{p}<0.05$ level

Table 2: Echocardiographic parameters

No changes were seen either in the TSD and TDD or in the thickness of the interventricular septum ( $p>0.05$ ); however, both groups showed a significant increase in nitrate concentration levels with no statistically significant differences between the exercise programmes (Table 3).

\begin{tabular}{|c|c|c|c|c|c|c|}
\hline & \multicolumn{2}{|c|}{ Water-based exercise program $(\mathbf{n = 1 2})$} & \multicolumn{3}{c|}{ Land-based exercise program (n=12) } \\
\hline$(\mathrm{pg} / \mathrm{ml})$ & Start & Finish & Relative difference & Start & Finish & Relative difference \\
\hline Nitrates & $65.4 \pm 26.9$ & $96.1 \pm 46.8 \mathrm{a}$ & $25.9 \pm 13.1$ & $54.3 \pm 17.6$ & $69.2 \pm 36.6 \mathrm{a}$ & $17.7 \pm 11.7$ \\
\hline Nitrites & $2.8 \pm 2.1$ & $2.5 \pm 0.8$ & $-0.6 \pm 0.6$ & $1.7 \pm 0.5$ & $1.5 \pm 0.5$ & $-0.3 \pm 0.2$ \\
\hline Adrenaline & $49.4 \pm 18.4$ & $57.6 \pm 34.1$ & $5.0 \pm 9.3$ & $67.5 \pm 30.5$ & $76.1 \pm 39.6$ & $7.4 \pm 8.9$ \\
\hline Noradrenaline & $914.8 \pm 407.7$ & $918.8 \pm 536.0$ & $8.4 \pm 146.9$ & $790.3 \pm 243.6$ & $833.5 \pm 441.3$ & $9.3 \pm 105.2$ \\
\hline Dopamine & $46.0 \pm 8.2$ & $52.3 \pm 19.1$ & $6.3 \pm 5.8$ & $56.3 \pm 14.6$ & $53.8 \pm 13.4$ & $-3.4 \pm 4.4$ \\
\hline
\end{tabular}

a significantly different from the Start value in the same group at the $\mathrm{p}<0.05$ level

Table 3: Concentration levels of oxidised nitric oxide metabolites and catecholamines 
Lastly, correlation analysis showed associations between the changes seen in the EF and in the level of nitrates ( $r=0.446 ; \mathrm{p}=0,042)$, as well as between the changes in IVC diameter and the variations seen in Ap-Am $(r=0.476 ; p=0,034)$.

\section{Discussion}

The changes in EF tally with those found in other studies both for water-based exercise programmes19, 21 and for land-based ones $[25,26]$ and could be attributable to the improvement in venous return, diastolic filling and myocardial contractility [26-28] and/ or afterload reduction [29].

As for heart-failure patients on beta-blockers, some studies have found significant changes in EF [13,30] while others have not observed any change following participation in exercise programmes [31,32]. The increase in nitrate levels observed in this study in both groups after three weeks of training could be related to the increase in EF. Indeed, changes in nitrate concentration were likely related to changes in endothelial function and significant correlations among increases in endothelium dependent vasodilation in vessels supplying the trained musculature and changes in EF and stroke volume were reported [7]. Accordingly, the decrease in resistance could correspond to an early effect of exercise. However, more studies are needed to clarify the changes to EF caused by exercise in patients being treated with beta-blockers [33].

Although not accompanied by an improvement in S and D, the changes seen in Am and Ap-Am, might also be due to an early improvement in diastolic function through a reduction in resistance to ventricular filling during atrial contraction and left ventricular end-diastolic pressures. So, to achieve a decrease in TDD and TSD, longer programmes might be required, as indicated by the findings of other studies [26].

The changes seen in Am and Ap-Am could be due to an improvement in cardiac distensibility, which aids cardiac filling. The ventricle relaxes faster and to a minimum pressure, thus increasing the pressure gradient between the left atrium (LA) and early diastolic filling without any increase in LA pressure. In actual fact the findings of our study indicate a slight increase in the E' wave although the changes are not statistically significant.

The improvement in systolic function is also accompanied by a normal thickening of the PW and hence by an improvement in contractility, as proposed by other authors in the absence of changes to ventricular diameters and volumes [28,34], with this thickening being greater in those subjects who followed the land-based exercise programme. Furthermore, in this group of patients the changes in relation to the initial E/Vp evaluation translate into an improvement in their prognosis owing to the considerable reduction in left ventricular filling pressures. As other authors have found, an E/Vp ratio of over 1.84 means an increase in telediastolic pressure [35]. So land-based exercise could aid diastolic filling by bringing down pressures compared with water-based exercise. This observation is in line with results already reported [22] and suggest that caution should be taken to use water-exercise in cardiac disease, especially with the weakest patients. Indeed, the myocardial compliance of the left ventricle could be compromised because of the enhanced preload induced by immersion [22].

Furthermore, the decrease in IVC diameter reflects an improvement in the rate of venous return. During immersion in water, the volume of intrathoracic blood is increased owing to a rise in venous return resulting from the effect of hydrostatic pressure on the capacitance of blood vessels, aided by a reduction in gravity. Hydrostatically, immersion in water causes a change in volume that could overload the adaptive cardiovascular mechanisms in patients with heart failure and lead to left ventricular decompensation, reducing systolic volume and increasing pressure; however the findings of this study show that it is well tolerated, probably because of the reduction in heart rate and the decrease in peripheral resistance [19,36]. Moreover, the decrease in filling resistance (Ap$\mathrm{Am})$ in the context of an increase in flow rate reflects an improvement in the heart's diastolic function.

For patients with heart failure, immersion in water induces a number of physiological reactions similar to those obtained by pharmacological means, such as a reduction in catecholamine levels; $[18,20]$ however, no significant changes have been seen in adrenaline, noradrenaline and dopamine levels in either of the two groups. As other authors have found, a reduction in these concentrations requires exercise programmes of a sufficient intensity and duration to bring about changes [37]. The short duration of the exercise programme in our study reduces the likelihood of significant changes occurring, and we therefore do not know if this would be different if part of the exercise programme were carried out in water.

In light of the above, we must also ask to what extent the amount and/or duration of water- and/or land-based exercise could have an effect on changes in heart function so that we are able to optimise the design of exercise programmes.

Our study has some limitations on account of its small sample size, which affects the significance of the findings, and because of the absence of a control group, which makes it impossible for us to establish the true extent of the effects of exercise on our heart function findings.

However, in spite of these limitations, the findings presented provide interesting information that could help in the design of other studies that would enable comparisons to be made and questions to be answered relating, for example, to the effect of programme duration or amount of exercise of whichever type on the changes in systolic and/or diastolic heart function in patients with heart failure. 
The changes in ventricular function seen in heart-failure patients taking part in a cardiac rehabilitation programme show early improvement in systolic and diastolic function independently of the type of exercise, but it seems to be that depending on the design of the programme, different adaptive mechanisms are set in motion. Studies involving larger samples are needed to enable us to have a more accurate understanding of the changes in ventricular function that come about in response to exercise in patients with heart failure.

\section{Acknowledgment}

This work was funded by grants from the French Ministry of National Education, of Research and of Technology (EA4660), by the Fédération Française de Cardiologie and the Fondation de l'Avenir. The authors thank the subjects for their time and cooperation and especially Alicia González Represas (Department of Functional Biology and Health Sciences, University of Vigo, Spain) for her help in the preparation of the manuscript.

\section{References}

1. Belziti CA (2001) Ejection fraction and ventricular volumes: old acquaintances with new clothes. Rev Argent Cardiol 69: 251-2.

2. Atehortúa DS, Gallo JA, Rico M, Durango L (2011) Effect of a cardiac rehabilitation program based on exercise on physical capacity, cardiac function and quality of life in patients with heart failure: Rev Colomb Cardiol 18: 25-36.

3. Martínez-Sellés M, García JA, Prieto L, Frades E, Muñoz R, et al. (2002) Characteristics of patients hospitalized for heart failure according to the state of ventricular function. Rev Esp Cardiol 55: 579-86.

4. Quiroz CA, Sarmiento J, Jaramillo C, Sanabria A (2010) Impact of cardiac rehabilitation in patients with heart failure of ischemic origin. Rev Colomb Cardiol 18: $10-24$.

5. Pina IL, Apstein CS, Balady GJ, Belardinelli R, Chaitman BR, et al. (2003) Exercise and Heart failure: a statement from the American Heart Association Committee on exercise, rehabilitation, and prevention. Circulation 107: 1210-25.

6. Working Group on Cardiac Rehabilitation (2001) Exercise Physiology and Working Group on Heart Failure of the European Society of Cardiology Recommendations for exercise training in chronic heart failure patients. Eur Heart J 22: 125-35.

7. Hambrecht R, Gielen S, Linke A, Fiehn E, Yu J, et al. (2000) Effects of exercise training on left ventricular function and peripheral resistance in patients with chronic heart failure: a randomized trial. JAMA 283: 3095-4101.

8. Braith RW, Welsch MA, Feigenbaum MS, Klues HA, Pepine CJ (1999) Neuroendocrine activation in heart failure is modified by endurance exercise training. J Am Coll Cardiol 34:1170-5.

9. Coats AJ, Adamopoulos S, Radaelli A, McCance A, Meyer TE, et al. (1992) Controlled trial of Physical training in chronic heart failure. Exercise performance hemodynamics, ventilation, and autonomic function. Circulation 85: 2119-31.

10. Belardinelli R, Georgiou D, Cianci G, Purcaro A (1999) Randomized, controlled trial of long-term moderate exercise training in chronic heart failure: effects on functional capacity, quality of life and clinical outcome. Circulation 9: 1173-82.

11. Piepoli MF, Davos C, Francis DP, Coats AJ (2004) Exercise training meta-analysis of trials in patients with chronic heart failure (ExTraMETCH). BMJ 328: 189-96.

12. Gianuzzi P, Temporelli PL, Corra U, Tavazzi L (2003) Antiremodeling effect of long term exercise training in patients with stable chronic heart failure: results of the Exercise in Left Ventricular Dysfunction and Chronic Heart Failure (ELVD-CHF) Trial. Circulation 108: 554-9.

13. Klecha A, Kawecka-Jaszcz K, Bacior B, Kubinyi A, Pasowicz M et al. (2007) Physical training in patients with chronic failure of ischemic origin: effect on exercise capacity and left ventricular remodeling. Eur J Cardiovasc Prev Rehabil 14: 85-91.

14. McKelvie RS, Teo KK, Roberts R, McCartney N, Humen D, et al. (2002) Effects of exercise training in patients with heart failure: the Exercise Rehabilitation Trial (EXERT) Am Heart J 144: 23-30.

15. Myers J, Wagner D, Schertler T, Beer M, Luchinger R et al. (2002) Effects of exercise training on left ventricular volumes and function in patients with nonischemic cardiomyopathy: application of magnetic resonance myocardial tagging. Am Heart J 144: 719-25.

16. Meyer K (2001) Exercise training in heart failure: recommendations based on current research. Med Sci Sports Exerc 33: 525-31.

17. Cider A, Schaufelberger M, Sunnerhagen KS, Andersson B (2003) Hydrotherapy—a new approach to improve function in the older patient with chronic heart failure. Eur J Heart Fail 5: 527-35.

18. Schmid JP, Noveanu M, Morger C, Gaillet R, Capoferri M, et al. (2007) Influence of water immersion, water gymnastics and swimming on cardiac output in patients with heart failure. Heart 93: 722-7.

19. Cider A, Sveälv BG, Täng MS, Schaufelberger M, Andersson B (2006) Immersion in warm water induces improvement in cardiac function in patients with chronic heart failure. Eur J Heart Fail 8: 308-13.

20. Gabrielsen A, Sorensen VB, Pump B, Galatius S, Videbaek R, et al. (2000) Cardiovascular and neuroendocrine responses to water immersion in compensated heart failure. Am J Physiol Heart Circ Physiol 279: H1931-40.

21. Tei C, Horikiri Y, Park JC, Jeong JW, Chang KS, et al. (1995) Acute hemodynamic improvement by thermal vasodilation in congestive heart failure. Circulation 91: 2582- 90 .

22. Meyer K and Bucking J (2004) Exercise in heart failure: should aqua therapy and swimming be allowed? Med Sci Sports Exerc 36: $2017-23$.

23. Sagiv MS (2012) Left Ventricular Function. In: Sagiv MS. Exercise Cardiopulmonary Function in Cardiac Patients. London: Springe 109-33.

24. Mourot L, Bouhaddi M, Gandelin E, Cappelle S, Dumoulin G, et al. (2008) Cardiovascular autonomic control during short-term thermoneutral and cool headout immersion. Aviat Space Environ Med 79:14-20.

25. Beer M, Wagner D, Myers J, Sandstede J, Köstler H, et al. (2008) Effects of Exercise Training on Myocardial Energy Metabolism and Ventricular Function Assessed by Quantitative Phosphorus-31 Magnetic Resonance Spectroscopy and Magnetic Resonance Imaging in Dilated Cardiomyopathy. J Am Coll Cardiol 51: 1883-91. 
26. Karapolat H, Demir E, Bozkaya YT, Eyigor S, Nalbantgil S, et al. (2009) Comparison of hospital-based versus home-based exercise training in patients with heart failure: effects on functional capacity, quality of life, psychological symptoms, and hemodynamic parameters. Clin Res Cardiol 98: 635-42.

27. Haykowsky M, Liang Y, Pechter D, Jones LW, McAlister FA, et al. (2007) A meta-analysis of the effect of exercise training on left ventricular remodeling in heart failure patients. J Am Coll Cardiol 49: 2329-36.

28. Belardinelli R, Georgiou D, Cianci G, Purcaro A (1996) Effects of exercise training on left ventricular filling at rest and during exercise in patients with ischemic cardiomyopathy and severe left ventricular systolic dysfunction. Am Heart J 132: 61-70.

29. Belardinelli R, Georgiu D, Ginzton L, Cianci G, Purcaro A (1998) Effects of moderate exercise training on thallium uptake and contractile response to low-dose dobutamine of dysfunctional myocardium in patients with ischemic cardiomyopathy. Circulation 97: 553-61.

30. Stolen KQ, Kemppainen J, Ukkonen H, Kalliokoski KK, Luotolahti M, et al. (2003) Exercise training improves biventricular oxidative metabolism and left ventricular efficiency in patients with dilated cardiomyopathy. J Am Coll Cardiol 5: 460-7.

31. Nechwatal RM, Duck C, Gruber G (2002) Physical training as interval or continuous training in chronic heart failure for improving functional capacity, hemodynamics and quality of life - a controlled study. Z Kardiol 91: 328-37.

32. Smart N, Haluska B, Jeffriess L, Case C, Marwick TH (2006) Cardiac contributions to exercise training responses in patients with chronic heart failure: a strain imaging study. Echocardiography 23: 376-82.

33. Mezzani A, Corrà U, Giannuzzi P (2008) Central adaptations to exercise training in patients with chronic heart failure. Heart Fail Rev 13: 13-20.

34. Belardinelli R, Georgiou D, Purcaro A (1998) Low-dose dobutamine echocardiography predicts improvement in functional capacity after exercise training in patients with ischemic cardiomyopathy: prognostic implication. J Am Coll Cardiol 31: 1027-34.

35. Schwammenthal E, Popescu BA, Popescu AC, Di Segni E, Guetta V, et al. (2004) Association of left ventricular filling parameters assessed by pulsed wave Doppler and color M-mode Doppler echocardiography with left ventricular pathology, pulmonary congestion, and left ventricular end-diastolic pressure. Am J Cardiol 94: 488-91.

36. Meyer K, Leblanc MC (2008) Aquatic therapies in patients with compromised left ventricular function and heart failure. Clin Invest Med 31 : E90-7.

37. Gademan MGJ, Swenne CA, Verwey HF, Van Der Laarse A, Maan RC, et al. (2007) Effect of exercise training on autonomic derangement and neurohumoral activation in Chronic Heart Failure. J Card Fail 13: 294-303.

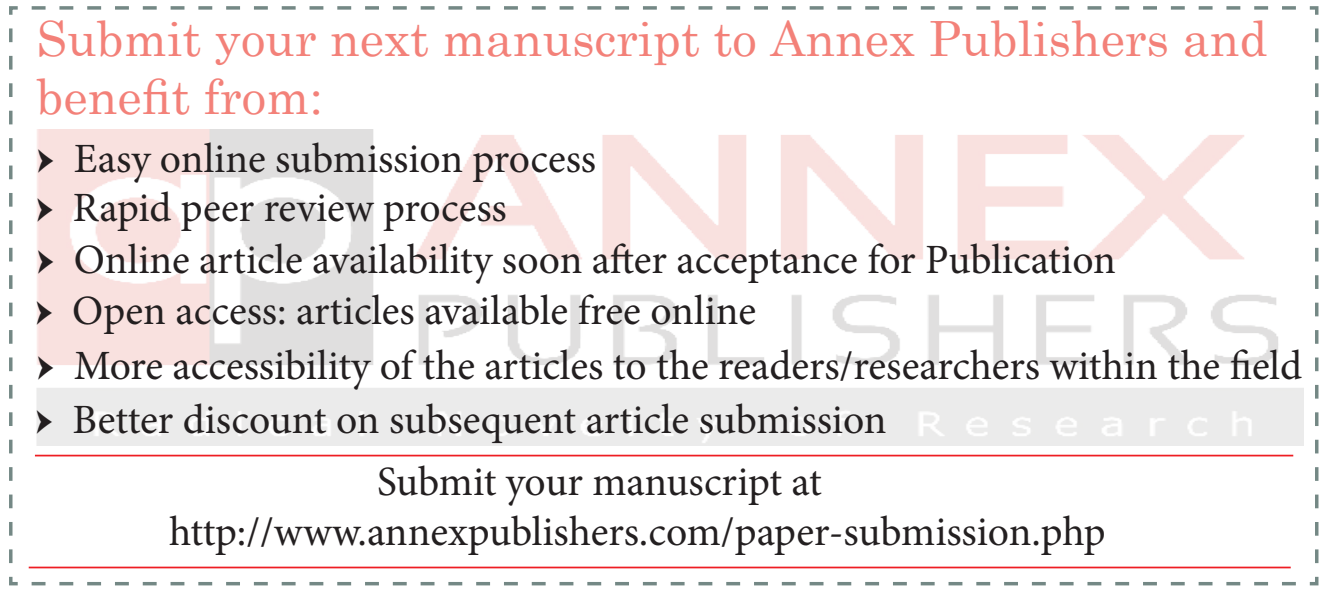

